\title{
Solid-Phase Synthesis for Beginners: Choice of Tools and Techniques for Implementation of Multistage Transformations
}

\author{
E. V. Babaev \\ Lomonosov Moscow State University, Vorob'evy Gory 1, Moscow, 119991 Russia \\ e-mail:babaev@org.chem.msu.ru
}

Received July 10, 2009

\begin{abstract}
Several mini-libraries were prepared by solid-phase synthesis: C,N-substituted glycines (1) and 2,5diaminobenzoic acids (2) using Wang resin as well as diarylthioureas (3) and diaryl-guanidines (4) using Rink resin. Comparative analysis of the instruments and technique for these reactions was provided by applying glass vials with filters (BillBoard kit) to prepare the class (1), the tea-bag technique for the class (2), and plastic rods (Lanterns) for the classes (3) and (4). All reactions (supplied with detailed protocols) were optimized for use as a tool of practical student education.
\end{abstract}

DOI: $10.1134 / \mathrm{S} 1070363210120261$

In [1] we remembered the $\mathrm{ABC}$ of solid-phase synthesis and dwelt in detail on the experimental problems associated with this technique. The principal inconvenience in the practical work with polystyrene resins is their tendency to swell in solvents. Solvents (and reagents) penetrate into the polymer globules, thus sharply increasing their volume. The gelatin-like nature of the swollen polymer makes it difficult to transfer from one vial to another or to a filter. In the present paper we analyze approaches to solving this problem. Three training tasks tested at the special student laboratory of combinatorial chemistry at the Moscow State University (MSU) were used as an example. In this work, we acquired a certain experience which can be useful for teachers and synthetic organic chemists.

Below we consider three examples of tools facilitating manipulations with polymer supports. In the first example, some problems are approached by the use of a container for resins and the BillBoard kit in which reaction vials are combined with filters. The chemical transformation is represented by double modification of a resin-immobilized protected glycine (consecutive $\mathrm{C}$-alkylation and $\mathrm{N}$-acylation). In the second example (the tea-bag technique), a resin is contained in a porous plastic bag, and the chemistry is presented by a multistage sequence of transformations. In the third example we consider the methodology of operation with specially modified polypropylene pins (lanterns), a new "synthesis philosophy" which radically changes all traditional views on modern organic synthesis. This technique was employed in a multistage (5-6 stages) synthesis of thioureas and guanidines. The three examples all represent versions of training tasks.

\section{BillBoard Technique}

Let us consider a four-stage modification of glycine (containing benzophenone protection) immobilized on the Wang resin. The main feature of the task is the use of a simple technical tool, the BillBoard kit, which is a specially designed set of filter tubes and convenient plastic facilities for stirring and filtering in several reaction vials. This is an inexpensive kit (if desired, its analog can be readily made) allows one to facilitate and speed-up manipulations when performing concurrent solid-phase reactions.

The suggested task was tested by a group of MSU students in the special laboratory course on combinatorial chemistry in 2005 . To fulfill the task, three laboratory lessons and a final seminar for purity analysis of the synthesized products (lesson 4) are required.

Chemical aspect of the task. The possibility of Calkylation of N-substituted amino acids immobilized 


\section{Scheme 1.}

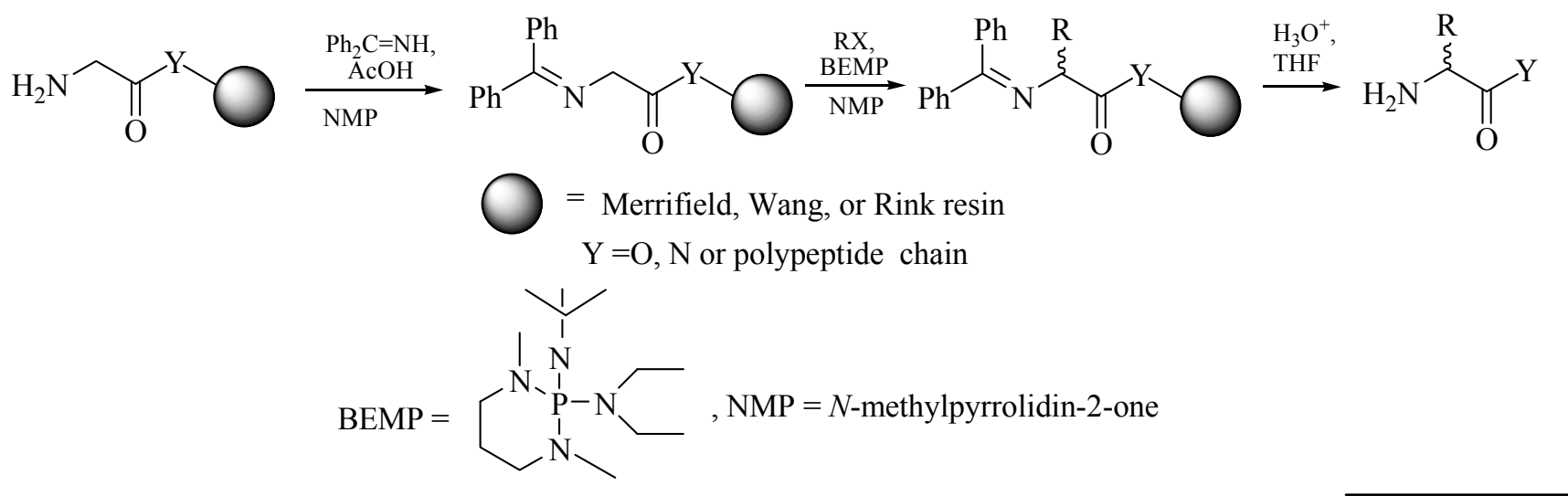

on a support has first been demonstrated 10 years ago [2] (Scheme 1).

The amino group in the resin-immobilized glycine is protected with the benzophenone fragment. The $\mathrm{CH}_{2}$ group of the resulting imine acquires sufficient acidity characteristic of azaallyl systems, and under the action of a strong base, for example, a substituted phosphazene (BEMP), it can be deprotonated and then Calkylated.

Since the first publications this line of research has substantially extended: Scott, O'Donnell, and coworkers [3-7] have published a big series of papers on the methodology of solid-phase synthesis by this reaction. Analogous reaction could be performed with low-active alkyl halides, as well as with alkenes (Michael reaction). Depending on the nature of the resin, different classes of compounds can be prepared: amides with the Rink resin and aminoaldehydes and aminoketones with the Weinreb resin. It was found that using strong bases allows preparation of Cdialkylated amino acids. The resulting immobilized intermediates can be reacted with nucleophiles or converted into more complex acyclic and cyclic systems, for example, proline derivatives, lactams, and hydantoins.

Specific features of the BillBoard kit. The facility and reproducibility of chemical transformations involving immobilized benzophenone imine derivatives of amino acids promted Prof. Scott to adapt these sequences for the student laboratory course in solidphase synthesis at the Indiana University (USA). The BillBoard training kit was constructed to facilitate concurrent manipulations with resins.

BillBoard is a specially designed set of filter tubes (Fig. 1a) with double-sided plastic screw caps with
Teflon septa (Fig. 1b). As a result, each vial plays the role of either a reaction vessel (when the caps are screwed) or a filter (when the caps are removed). The filter is soldered unsymmetrically, and the solid support is placed in a larger vial compartment. The tubes are fixed in a special plastic holder (BillBoard as such, Figs. 1b and 1c) which can be used both as a stand (on adding reagents, washing tube contents, and filtering) and as a block for simultaneously rotating and agitating six vials. Two convenient plastic accessories (Fig. 1c) serve as receivers for washings or stands for collection of final cleavage products, respectively. For agitating several BillBoards one can use simple accessories (Fig.1d, see also Figs. 2e and 2f).

A complete synthetic kit costs 175 USD, it is designed for multiple use and allows 6 concurrent combinatorial solid-phase reactions. The simplicity and low cost of the kit allowed successful solid-phase combinatorial syntheses to be performed by students and $\mathrm{PhD}$ students not only at the Indiana University, but also at the universities of Barselona (Spain) and Lublin (Poland). In 2005, the BillBoard was acquired by the special student laboratory of combinatorial chemistry at the MSU, and in the framework of Prof. Scott's visit to Moscow we practically implemented the task with a group of students and $\mathrm{PhD}$ students of the Chemical Department.

Brief description of the task. The task involves four stages: (1) alkylation of the $\mathrm{CH}_{2}$ group of an amino acid immobilized on the Wang resin (W); (2) removal of the protective group; (3) acylation of the $\mathrm{NH}_{2}$ group of the amino acid; and (4) removal of the doubly modified amino acid from the support (Scheme 2).

Each student performed simultaneously six syntheses, using three benzylating and two acylating agents, 
Scheme 2.

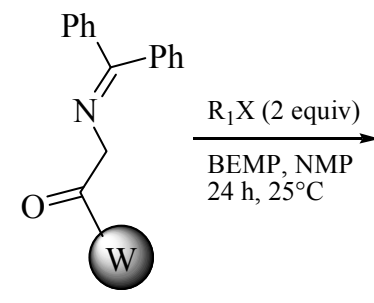

I

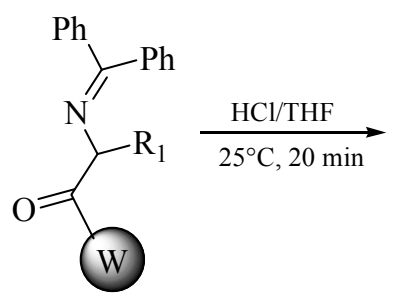

II

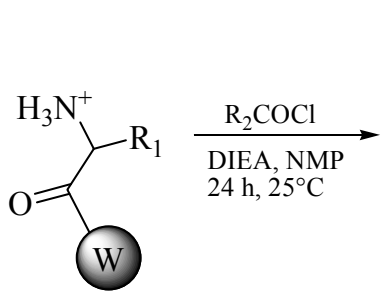

III

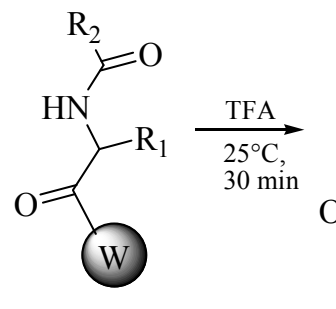

IV<smiles>[R]C(=O)NC([R])C(=O)O</smiles>

V in a single BillBoard labeled according to Scheme 3 (A, B and I, II, III).

Reagents: resin I (protected glycine on the Wang resin) $2 \mathrm{~g}$, phosphazene base BEMP (Aldrich-79432, see the formula in Scheme 1) $5 \mathrm{ml}$, diisopropylethylamine (DIEA) $100 \mathrm{ml}$, TFA (99\%) $100 \mathrm{~g}$, and aqueous $\mathrm{HCl}(1 \mathrm{~N}) 50 \mathrm{ml}$. Solvents: 11 of $\mathrm{N}$-methylpyrrolidin-2-one (NMP) and by $100 \mathrm{ml}$ of dichloromethane (DCM), THF, and DMF (the latter is needed for rinsing caps of reaction vials).

The alkylating agents were three benzyl bromides (from 1 to $5 \mathrm{~g}$ ): unsubstituted benzyl bromide and its (a)

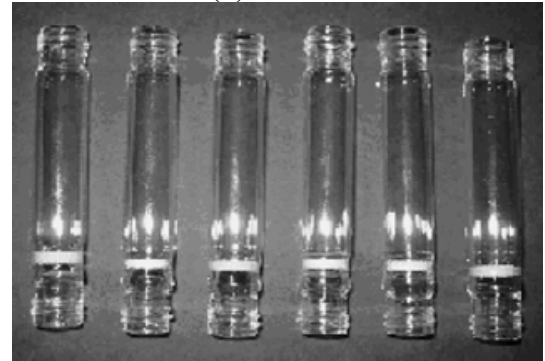

(c)
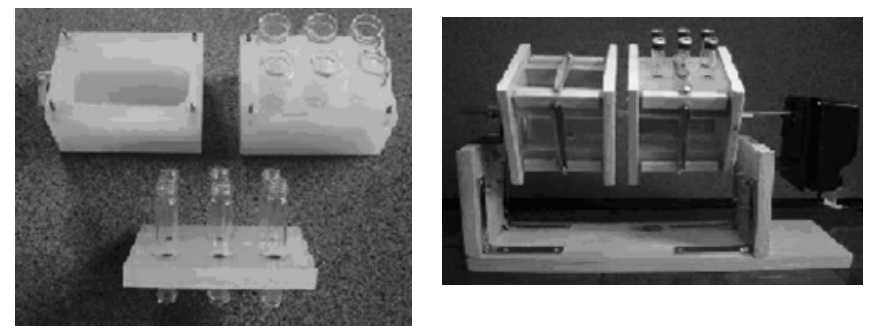

(b)

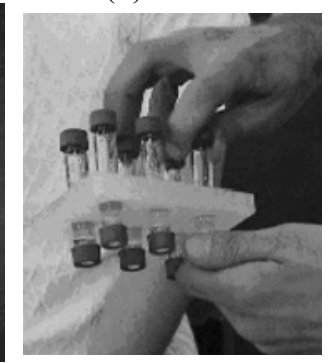

(d)
Fig. 1. BillBoard kit: (a) double-ended filter vials; (b) fixing of reaction vials; and (c) additional plastic collectors: (left) for washings, (right) for final products, (bottom) BillBoard ready for fixing; and (d) option for simultaneous agitation of six reaction vials. A simple facility allows to fix eight BillBoards and simultaneously agitate 48 vials. $m$-bromo and $p$-trifluoromethyl derivatives; at the MSU we used additionally a pyridine analog, specifically 2-chloro-5-(chloromethyl)pyridine. Compounds with a high molecular weights, 9-fluorenyl chloroformate (Fmoc-Cl) and 2-naphthoyl chloride (by $5 \mathrm{~g}$ ), were recommended as acylating agents.

\section{Lesson 1. Alkylation}

(1) Preparation of an isopycnic solution of glycine imine I immobilized on the Wang resin, based on $65 \mathrm{mg}(50 \mathrm{mmol})$ per one experiment (resin capacity $\left.0.77 \mathrm{mmol} \mathrm{g}^{-1}\right)$.

Two solvents with different densities, for example, THF and DCM, are added to a dry resin. By varying their ratio one can obtain a homogeneous (as much as practical) gel, when resin particles neither float nor precipitate.

At the beginning of the first laboratory lesson students get 6 reaction vials placed in a BillBoard and a solution of resin I (Fig. 2a).

(2) The required volume of the isopycnic solution is distributed between vials, after which the solvent is allowed to drain. To expel residual solvent, a simple pump can be used. The resin in each reaction vessel is

Scheme 3.

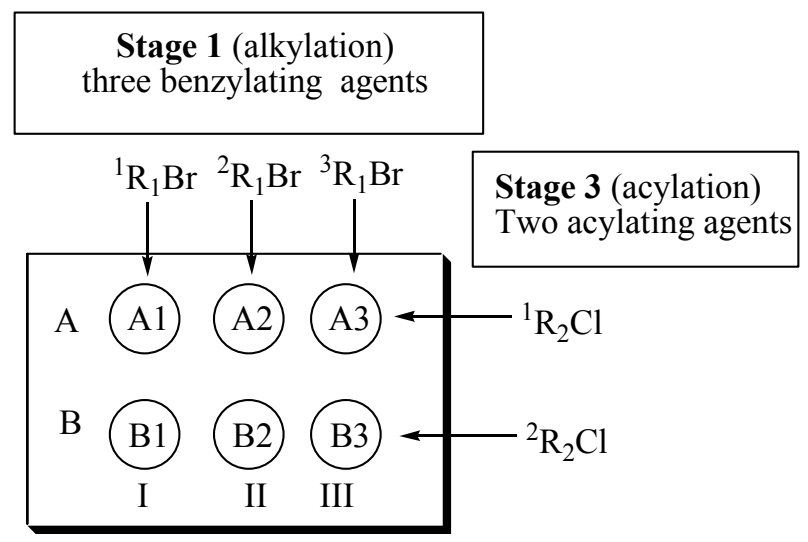


washed with NMP $(3 \times 3 \mathrm{ml})$ by means of a $3.5-\mathrm{ml}$ plastic Beral pipette. At all stages of the work, one should meet the following instructions.

I. General washing procedure. Washings should be always performed in a strictly specified order. The washing liquid, $\sim 3 \mathrm{ml}(\sim 80 \%$ the total volume of the reaction vial), is added with a $3.5-\mathrm{ml}$ pipette. Wait for $30 \mathrm{~s}$ to let the solvent to drain through the filter under the gravitation force. Then the resin should be dried completely (pump purging) (Fig. 2b). A glass should be put beneath the drain pan plug. Finally, the liquid in the glass should be poured into a waste container.

II. Use of air pump. The "pump" is a piece of a rubber tube with one end of each plugged with a plastic Beral pipette and the second end attached to a septa with a through slot. When the solvent has drained through the filter (within $30 \mathrm{~s}$ ), attach the pump (from the septa side) to the vial neck and press the extended part of the pipette. To avoid back soaking of the solvent from the vial to tube, raise slightly the septa over the neck and only then unfold fingers. Repeat the procedure until all solvent drains through the filter.

III. Manipulations with caps of reaction vials. Before screwing the cap remove solvent residues from the space between the cap and vial by means of a soft cloth. Before unscrewing turn the side of the BillBoard to be opened up. Unscrew the cap, turn the BillBoard around and put it into the pan. Shake BillBoard several times to make sure that all gel residues are removed from inner side of the cap. Open the top caps of all reaction vials and put them into a glass for further use.

(3) Mount the BillBoard to a special holder. Screw the bottom caps (closest to soldered-in filters) of each reaction vial (Fig. 2c).

(4) Prepare three calibration Beral pipettes for adding benzylating agents ${ }^{1} \mathrm{R}_{1}-\mathrm{Br},{ }^{2} \mathrm{R}_{1}-\mathrm{Br}$, and ${ }^{3} \mathrm{R}_{1}-\mathrm{Br}$ (separate pipette for each reagent). Safety measures: glasses and gloves!

(5) Add by $0.5 \mathrm{ml}$ of $0.2 \mathrm{M}$ solutions of alkylating agents in NMP (100 mmol, 2 equiv). Respectively, ${ }^{1} \mathrm{R}_{1}-\mathrm{Br}$ is added to the reaction vials in the first vertical column (A1 and B1), ${ }^{2} \mathrm{R}_{1}-\mathrm{Br}$, to the vials in the second vertical column (A2 and B2), and ${ }^{3} R_{1}-B r$, to $A 3$ and B3 (Scheme 4).

Add by $0.5 \mathrm{ml}$ of a $0.2 \mathrm{M}$ solution of BEMP in NMP (100 mmol, 2 equiv) in each of the six reaction vials. Screw the top caps of the BillBoard and mount it to a rotating apparatus (Figs. 2e and 2f). Record reaction initiation time and the BillBoard number. Reaction time $24 \mathrm{~h}$. This reaction (and all subsequent reactions) are performed at room temperature. Before leaving the laboratory, wash the drain tray with acetone over the waste container. (a)

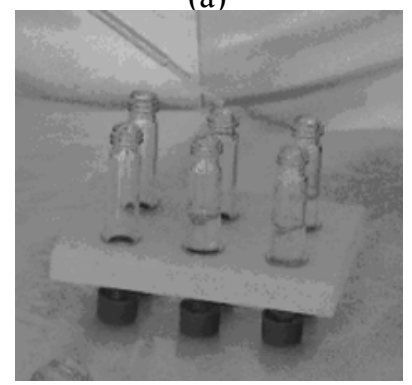

(d)

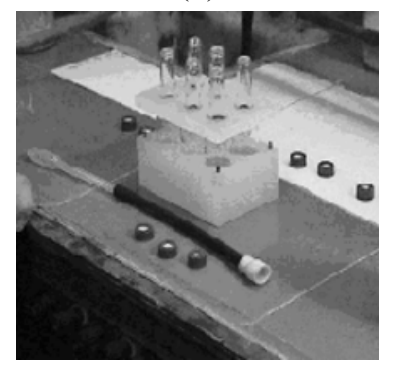

(b)

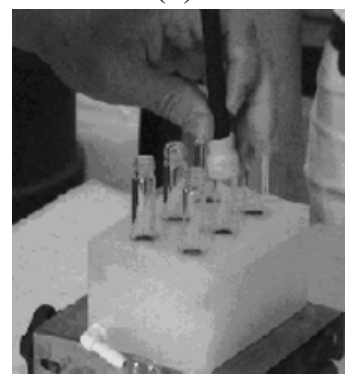

(e)

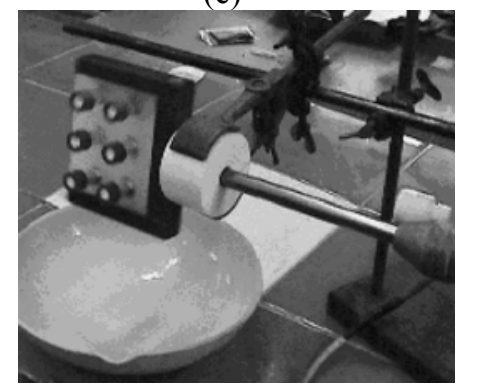

(c)

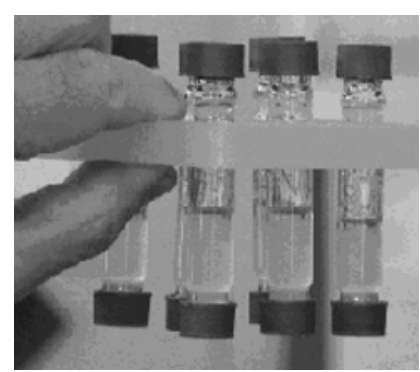

(f)

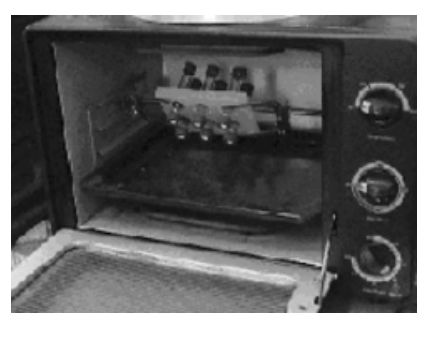

Fig. 2. Features of practical implementation of the task: (a) addition of reagents at the first stage (lower caps are closed); (b) pumpdrying of resins on filters; (c) view of a closed BillBoard during reaction, (d) removal of products from resins (under hood!), (e, f) different variants of mixing in 6 reaction vials. 
Scheme 4.<smiles>O=C(CN=C(c1ccccc1)c1ccccc1)c1ccccc1</smiles>

I

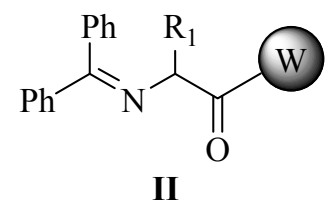

Lesson 2. Protection Removal and N-Acylation

(6) Record reaction completion time and take the BillBoard out of the rotating apparatus. Unscrew the caps as recommended in Instruction III.

(7) Wash out excess reagents from the resin. Wash the alkylated resin (product II) one time with $3 \mathrm{ml}$ of THF and pump-dry (Instruction II).

(8) Mount the BillBoard on a holder. Take 12 clean caps, screw the bottom caps of each reaction vial and add about $2.5 \mathrm{ml}$ of a $1 \mathrm{~N}$ aqueous solution of a 1:2 $\mathrm{HCl}-\mathrm{THF}$ mixture to each vial. Screw the top caps and place in the rotating apparatus for $20 \mathrm{~min}$ (Scheme 5).

Scheme 5.

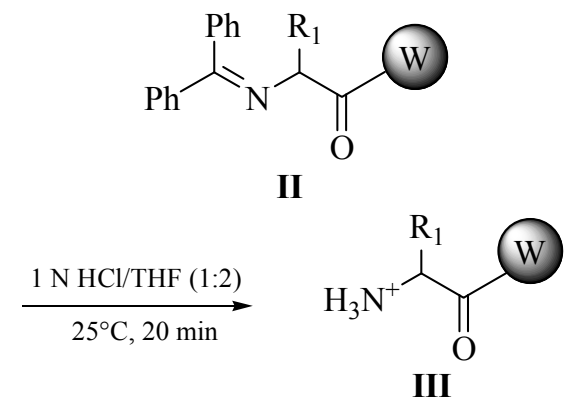

(9) Unscrew all caps.

(10) Filter off and wash product III in succession with $3 \mathrm{ml}$ of THF and $3 \mathrm{ml}$ of NMP (one time).

(11) Mount the BillBoard on a holder. Take 12 clean caps. Screw the bottom caps of each reaction vial and add $0.5 \mathrm{ml}$ of a $0.2 \mathrm{M}$ solution of the first acylating agent ${ }^{1} \mathrm{R}_{2}-\mathrm{COCl}$ in NMP (100 mmol, 2 equiv) to resin III in the three reaction vials in the first horisontal row (A1, A2, and A3). Then add $0.5 \mathrm{ml}$ of a $0.2 \mathrm{M}$ solution of the second acylating agent ${ }^{2} \mathrm{R}_{2}-\mathrm{COCl}$ in NMP ( $100 \mathrm{mmol}, 2$ equiv) to resin III in the three reaction vials in the second horizontal row (B1, B2, and B3). Then add $0.5 \mathrm{ml}$ of a $0.3 \mathrm{M}$ solution of DIEA in NMP
( $150 \mathrm{mmol}, 3$ equiv) to each of the six reaction vials. Screw the top caps. The reaction is performed for $24 \mathrm{~h}$ in the rotating apparatus (Scheme 6).

\section{Scheme 6.}<smiles>[R]C([NH3+])C(=O)c1ccccc1</smiles>

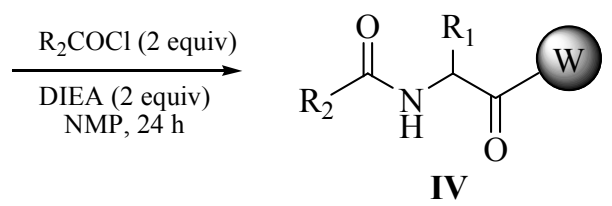

Lesson 3. Removal of N,C-Substituted Amino Acid from Support

(12) Take the BillBoard out of the rotating apparatus and unscrew caps (Fig. 2d).

(13) Filter off and wash product IV with NMP $(2 \times 3 \mathrm{ml})$, THF $(2 \times 3 \mathrm{ml})$, and $\mathrm{CH}_{2} \mathrm{Cl}_{2}(3 \times 3 \mathrm{ml})$.

(14) Mount the BillBoard on a holder. Screw the bottom end with clean caps. Add $2 \mathrm{ml}$ of $\mathrm{CF}_{3} \mathrm{COOH} /$ $\mathrm{H}_{2} \mathrm{O}(95: 5)$ to each vial. Take caution! Screw the top caps and place the BillBoard in a rotating apparatus for 30 min (Scheme 7).

Scheme 7.<smiles>[R]C(=O)NC([R])C(=O)c1ccccc1</smiles>

IV

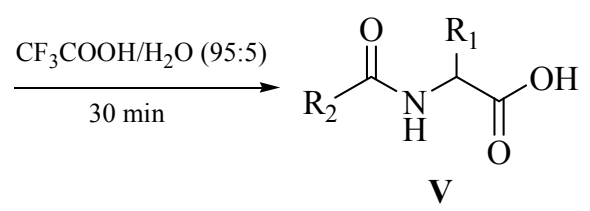

(15). As the cleavage reaction is in progress, prepare six weighed receiver vials, label them (A1B1, A1B2, etc.), and place in a 6-hole rack.

(16) Products $\mathbf{V}$ which are now in a solution (therefore, one should preserve the filtrate) transfer to the vials. To this end, turn the Billboard over (the bottom caps up), unscrew these caps, and mount receivers on the reaction vials. Make sure that the labels on the reaction and receiver vials are the same. Having accommodated all vials, mount the rack on them, and turn over the whole construction. Unscrew 
Scheme 8.

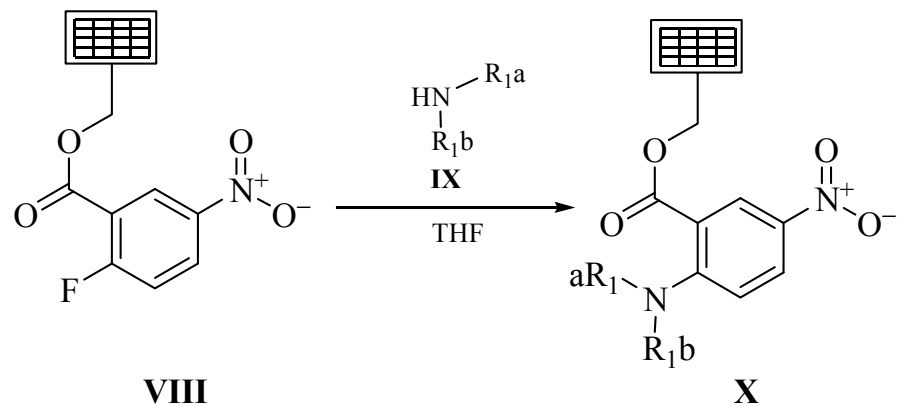<smiles></smiles><smiles>[R]C(=O)Nc1ccc(N([R10])[R17])c(C(=O)O)c1</smiles>

the upper caps and collect the filtrate into vials, using a pump.

(17) Wash the resins one time with $2 \mathrm{ml}$ of $\mathrm{CF}_{3} \mathrm{COOH}-\mathrm{H}_{2} \mathrm{O}(95: 5)$ and one time with $2 \mathrm{ml}$ of $\mathrm{CH}_{2} \mathrm{Cl}_{2}$, collecting washings into receiver vials. Every time pump the solvent thoroughly down.

(18) Take the BillBoard off from the vials. Transfer by $0.1 \mathrm{ml}$ of each sample of product $\mathbf{V}$ into vials for subsequent LC/MS analysis (Fig. 3). The vials with final products transfer to a vacuum drying oven for evaporation. (Evaporation can also be performed on a rotary evaporator in weighed flasks).

(19) Wash the drain pan and BillBoard with acetone.

\section{Lesson 4. Determination of Product Yields and TLC Analysis}

(20) Weight all final products. (Taking into account that the reactions are performed on a $50 \mu \mathrm{mol}$ scale, and the molecular weights of products vary in the range $300-400 \mathrm{~g} \mathrm{~mol}^{-1}$, the theoretical yield in each reaction should be $15-20 \mathrm{mg}$ ). The real yield is $10-15 \mathrm{mg}$.

(21) For TLC dissolve each product in THF (about $0.1 \mathrm{ml}$ of THF per $1 \mathrm{mg}$ of product) and use the system $\mathrm{CHCl}_{3} / \mathrm{THF} / \mathrm{CH}_{3} \mathrm{COOH}$ (85/15/2). Develop the chromatograms first under UV light and then with iodine. Record $R_{f}$ in both cases. As references use earlier synthesized samples. 
Moscow-A1 Sm (Mn, 1×1)

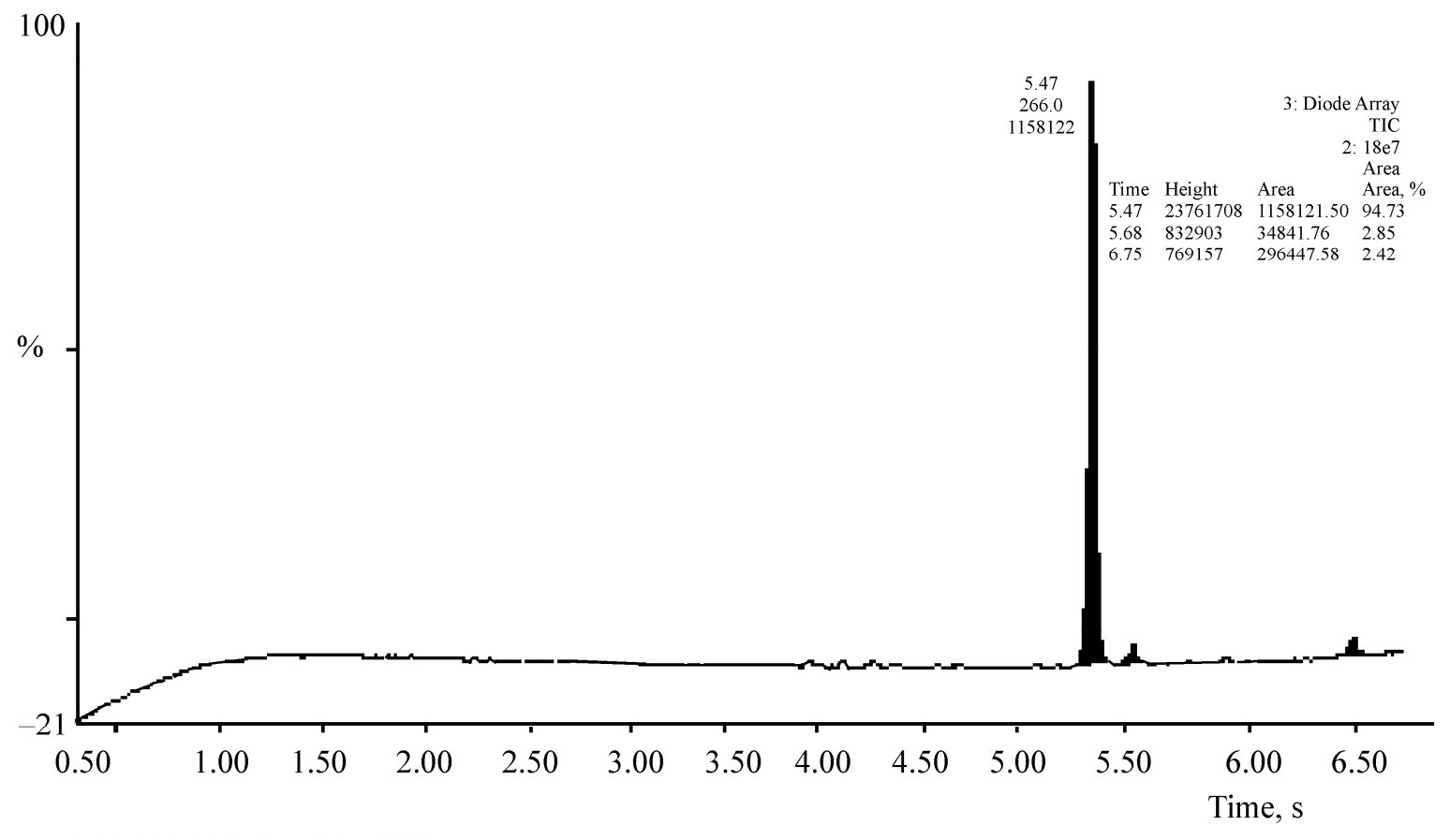

Moscow-A1 206 (5.514) Cm (205:209)

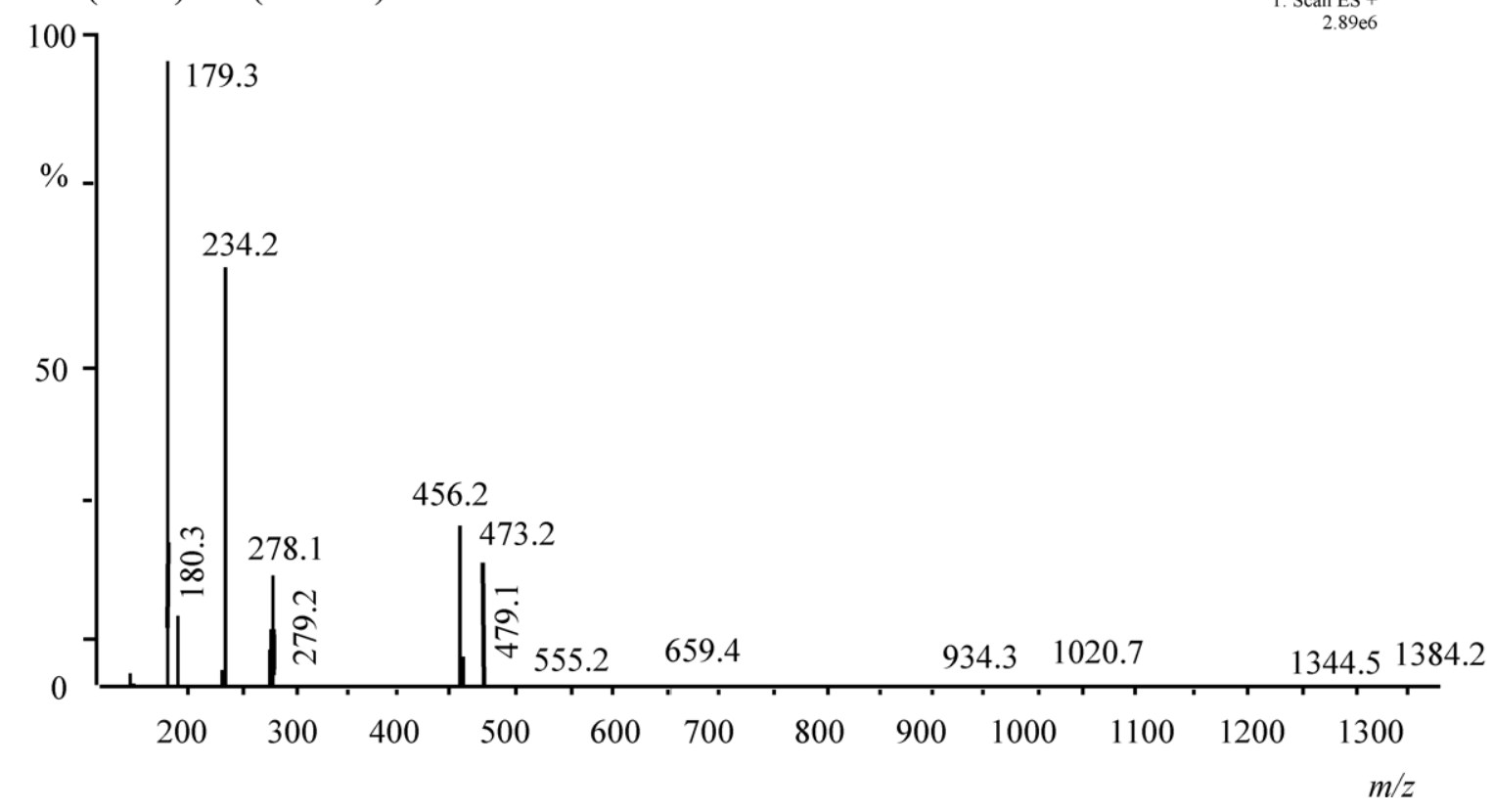

Fig. 3. Example LC-MS data for sample A1 (purity $95 \%$, calculated for $\mathrm{C}_{25} \mathrm{H}_{20} \mathrm{~F}_{3} \mathrm{NO}_{4}: M 455$ ).

The results obtained in the same combinatorial task in several universities all over the world formed the basis for quite an unusual concept named "Distributed Drug Discovery." Its essence consists in that students of different universities fulfilling the same training task obtain eventually a fairly representative combinatorial library of potential drugs. Synthesis and subsequent testing are planned from a united center
[8]. The contribution of the Moscow team into this project is described in a separate paper [9].

\section{Tea-Bag Technique}

This technique is a result of a long-term collaboration between the Chemical Diversity Research Institute (CDRI, Khimki) and Higher Educational Institutions of Moscow. The laboratory work was 
(a)

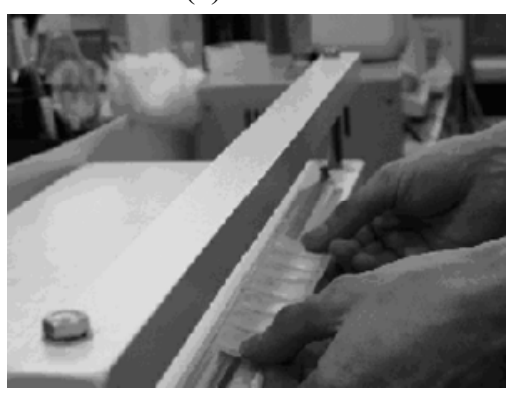

(c)

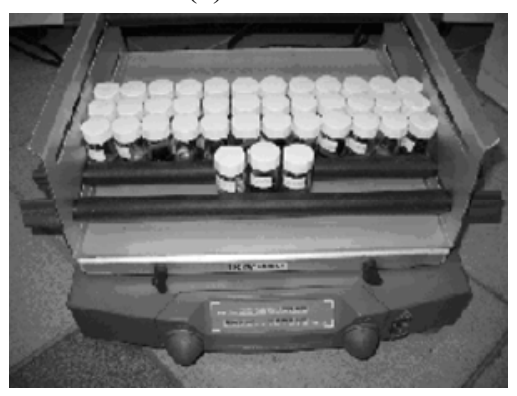

(b)

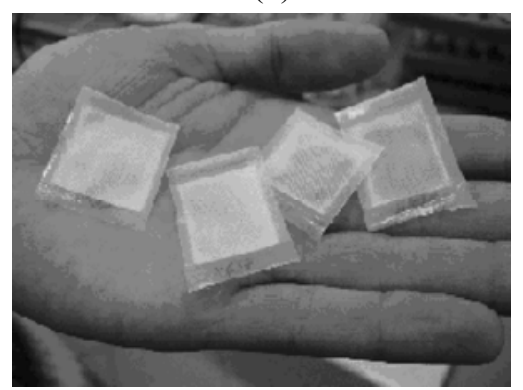

(d)

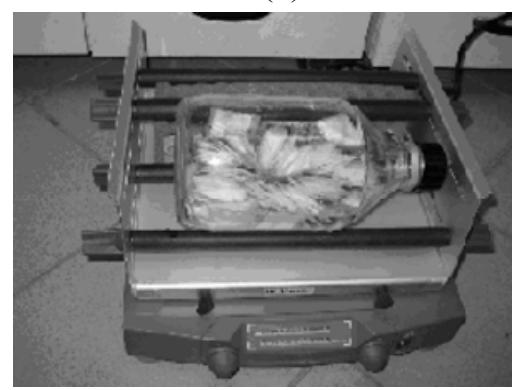

Fig. 4. Scheme of the tea-bag technique.

developed based on the practical experience in solidphase synthesis, accumulated at the CDRI. Students of the MSU, involved in fulfilling the tasks of the special laboratory course in combinatorial chemistry could get familiar with the CDRI's procedures during excursions to this institute or Open Days (held since 2004). Below we describe the procedure of a student training task for such special laboratory courses.

The laboratory work is based on a technique widely used in solid-phase synthesis and called the tea-bag technique. The container for resin here is a bag of a porous plastic film sealed over the entire perimeter, for example, using a simple hot cutter (Fig. 4a). Such bags (Fig. 4b) can be easily made, put in a great number of vials to add similar reagents (Fig. 4c) or combined and put in one vial (Fig. 4d) to add the same reagent or at repeated resin washing stages. Naturally, the resin swelling effect is unavoidable, but here one can fully avoid resin sticking to glass vial walls. Morever, bags can function as a vessel and a filter simultaneously.

Reaction sequence. As a model chemical reaction we chose a sequence shown in Scheme 8. 2-Fluoro-5nitrobenzoic acid, a compound containing a halogen activated for nucleophilic substitution and a nitro group which can be readily reduced to form an amino function and then acylated by the latter, is immobilized on the Wang resin. Theoretically, the starting acid a three-point template, since the third function (carboxyl), too, can be easily converted into, for example, an amidy one. However, in the task under consideration, a shortened sequence is used, and the target products are substituted 2,5-diaminobenzoic acids XV.

Required reagents and equipment. The Wang resin, film for bags, and instrumentation for fabrication of the latter are required, as well as a large volume of different solvents, a series of secondary aliphatic amines, chlorides of aromatic (including heteroaromatic) carboxylic acids, $\mathrm{SnCl}_{2}$, pyridine, acetic anhydride, and trifluoroacetic acid. The work is performed on a shaker (mostly at room temperature); varied-size capped vials are used as reservoirs for bags with resins.

Stage 1. Immobilization of 2-fluoro-5-nitrobenzoic acid on the Wang resin.

Wang resin VII (50 g, capacity $2.00 .77 \mathrm{mmol} \mathrm{g}^{-1}$ ) is suspended in a solution of $0.2 \mathrm{~mol}$ of 2-fluoro-5nitrobenzoic acid VI (37.41 g) and $25 \mathrm{mg}$ of 4 -(dimethylamino)pyridine in $400 \mathrm{ml}$ of absolute dichloromethane (DCM), after which $31.5 \mathrm{ml}(0.2 \mathrm{~mol})$ of diisopropylcarbodiimide was added with caution. The reaction mixture is shaken for 2 days at room temperature. The resin is filtered off and washed with solvents in the following order: $2 \times \mathrm{DCM}$, DMF, $\mathrm{MeOH}, 2 \times \mathrm{DCM}, 2 \times \mathrm{MeOH}, 2 \times \mathrm{DCM}$, and $2 \times$ hexane, and vacuum-dried. Resin VIII is ready for further use. 
<smiles>O=C(O)c1cc([N+](=O)[O-])ccc1CO</smiles><smiles>O=C(OCc1ccccc1)c1cc(N(O)O)ccc1F</smiles>

Stage 2. Substitution of fluorine by dialkylamino group.

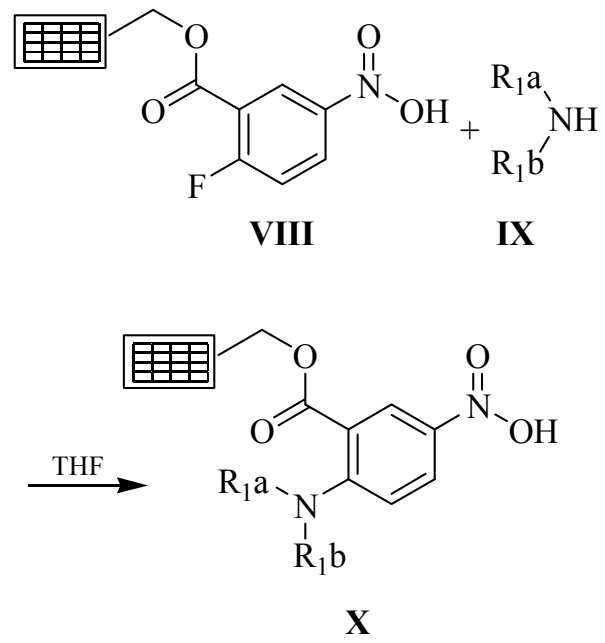

Resin VIII is distributed over plastic bags (Figs. 4a and $4 \mathrm{~b}$ ) whose number is equal to the number of final products. The resin weigh is a bag is $250 \mathrm{mg}$ (capacity $1.50 .77 \mathrm{mmol} \mathrm{g}^{-1}$ ). According to the statements of work (which specify what amine to take and how many experiments to perform), the bags are distributed over vials equal in number to the number of amines (Fig. 4c). The bags are labeled.

Each vial is charged with a solution of a required amine dissolved in THF ( 5 equiv or $1.9 \mathrm{mmol}$ per one portion of resin). The vials are agitated on a shaker for $18 \mathrm{~h}$. The bags are washed successively with $2 \times \mathrm{THF}$, DMF, $2 \times \mathrm{MeOH}, 2 \times \mathrm{DCM}$, and $2 \times$ hexane. As a result, fluorine in resin VIII is substituted with the corresponding dialkylamino group to form resin $\mathbf{X}$.

This stage involves one important operation (capping). The case in point is that secondary amines partially destroy the ester bond which links the substituted benzoic acid to polymer. As a result, part of hydroxymethyl groups of the resin get free and can function as a competitive center at the subsequent acylation stage. Since the acylating agent at stage 4 are derivatives of aromatic acids, the introduced acyl residues will persist on the resin until the last stage and contaminate the final product at the linker cleavage stage. Therefore, the hydroxymethyl groups should be protected by a "harmless" residue of a water-soluble acid, say, acetic.

In practice, the resins are placed in a pyridine solution and then acetic anhydride is added. The quantities of reagents are estimated as follows: 5 equiv (1.9 mmol, $0.204 \mathrm{ml})$ of pyridine in abs. DCM per one bag and 5 equiv $(1.9 \mathrm{mmol})$ of acetic anhydride. The vials are agitated in a shaker for $18 \mathrm{~h}$ at room temperature. The resins are washed in succession with $2 \times \mathrm{THF}, \mathrm{DMF}, 2 \times \mathrm{MeOH}, 2 \times \mathrm{DCM}$, and $2 \times$ hexane and vacuum-dried to obtain products $\mathbf{X}$.

Stage 3. Reduction of nitro group.

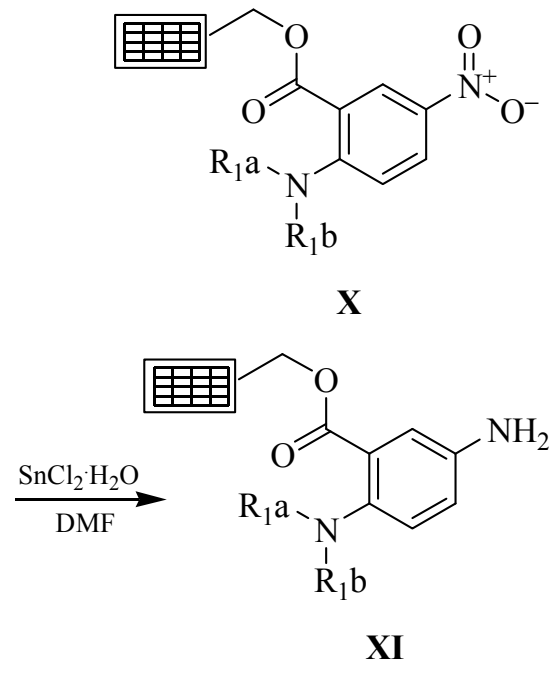

Since we used the same reaction for all resins $\mathbf{X}$, the labeled bags are put in one reaction vessel (Fig. 1d), after which a $2 \mathrm{M}$ solution of $\mathrm{SnCl} 2 \times 2 \mathrm{H}_{2} \mathrm{O}$ in DMF (50 $\mathrm{ml}$ per $1 \mathrm{bag}$ ) and shaken at room temperature for $48 \mathrm{~h}$. The bags are successively washed with $2 \times \mathrm{DMF}, 2 \times \mathrm{DMF} / \mathrm{H}_{2} \mathrm{O}(1: 1 \mathrm{v} / \mathrm{v}), 2 \times \mathrm{H}_{2} \mathrm{O}$, $2 \times \mathrm{DMF}, 2 \times \mathrm{MeOH}, 2 \times \mathrm{DCM}, 2 \times \mathrm{MeOH}, 2 \times \mathrm{DCM}$, and $2 \times$ hexane and vacuum dried to obtain resins XI with a free amino group.

Stage 4. Acylation of amino group.

The operation is performed in two stages. To prevent incomplete reaction, conditions to ensure 
double acylation of the aniline amino group are chosen. At the following stage, mild removal of one of the amino groups is accomplished, whereas the second amino group remains intact.

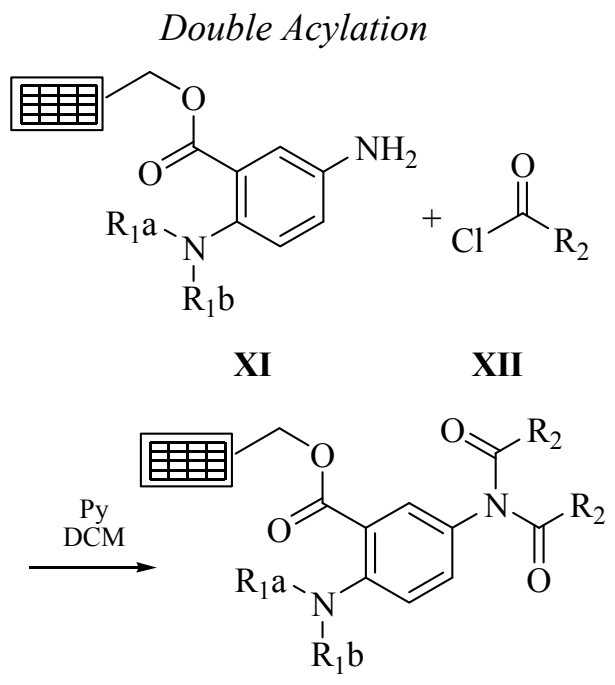

XIII

According to the statements of work (which specify how many experiments to perform and what acylating agent to take), the bags with resins VI are again distributed over vials whose number is equal to the number of acyl chlorides (Fig. 4c). The bags are again labeled.

To each vial, 5 equiv $(1.9 \mathrm{mmol})$ of pyridine in abs. DCM and acyl chloride VII (5 equiv or $1.9 \mathrm{mmol}$ per one portion of resin) are added. The vials are agitated in a shaker at room temperature for $6-18 \mathrm{~h}$. The bags are washed in succession with $2 \times \mathrm{DCM}, 2 \times \mathrm{DMF}$, $2 \times \mathrm{MeOH}, 2 \times \mathrm{DCM}, 2 \times \mathrm{MeOH}, 2 \times \mathrm{DCM}$, and $2 \times$ hexane and dried to obtain diacyl derivatives XIII.

\section{Removal of One of the Acyl Groups}

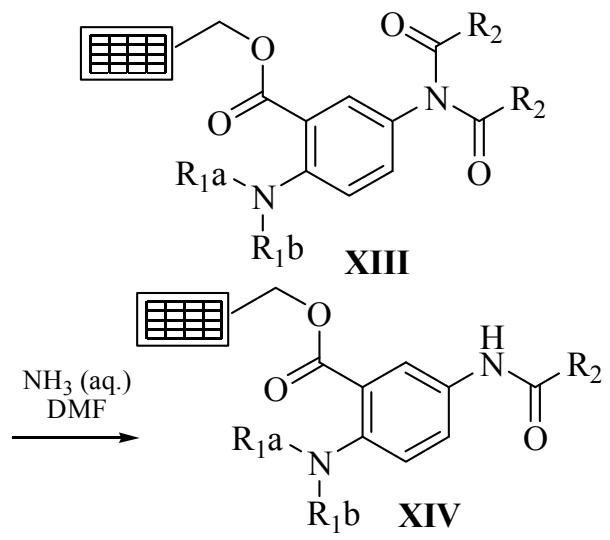

The bags with resins XIII are placed into a $25 \%$ solution of aqueous ammonia in DMF, agitated in a shaker at room temperature for $18 \mathrm{~h}$, and washed with $2 \times \mathrm{DMF}, 2 \times \mathrm{MeOH}, 2 \times \mathrm{DCM}, 2 \times \mathrm{MeOH}, 2 \times \mathrm{DCM}$, and $2 \times$ hexane to obtain monoacyl derivatives XIV.

Stage 5. Removal of the final product from support.<smiles>[R]C(=O)Nc1ccc(N([R16])[R16])c(C(=O)OCC2=CC=C2)c1</smiles>

XIV<smiles>[R]C(=O)Nc1ccc(N([R17])[R17])c(C=O)c1</smiles>

XV

Each bag is placed into an individual vial, treated with $10 \%$ TFA/DCM, and left to stand at room temperature for $2 \mathrm{~h}$. The solution is decanted and the solvent was removed at reduced pressure to obtain final products $\mathbf{X V}$.

Yield and purity of the obtained products. The isolable yields of products by $100 \mathrm{mg}$ of the initial resin is, on average, $150 \mathrm{mg}$. The purity of final samples XV, determined by LC-MS (UV-254 and ELSD detectors) was $>90 \%$.

\section{Syntheses with Lantern Rods}

The problem of polymer swelling (which complicated the transfer of resins from one vessel to

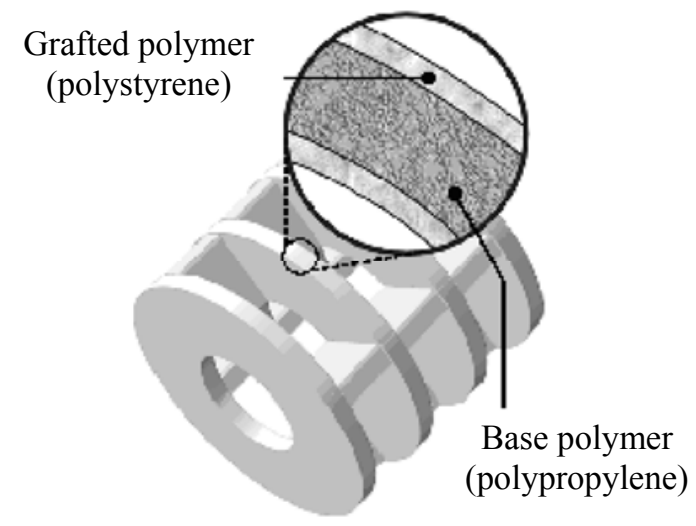

Fig. 5. Lantern structure. 
another, or to a filter) is solved to success by using a filter tube "container" or a "tea bag." At the same time, one more inconvenience takes place: A fairly large volume of solvents is required to thoroughly wash out excess reagents from pores and internal volume of polymer particles. An ideal solution would be to use a nonswelling polymer like polypropylene. Unfortunately, the desired functional groups (and in the required quantity) are difficult to graft on the polypropylene surface. (With polystyrene, this is readily accomplishable by, for example, chloromethylation). An original solution is to use a polypropylene support surface-coated with a thin polystyrene film. Just this principle forms the basis of the Mimotopes's lantern technology.

Lantern is a plastic polypropylene cylinder coated with chemically modified polystyrene. To increase the total volume, an internal cavity and slots are made in the cylinder surface (thus making it similar to a Chinese lantern, Fig. 5). The dimensions of lanterns are chosen so that they fit the cavity of standard plastic billets $(8 \times 12)$. By immersing lantern into various reagents (Fig. 2b) and washing it every time with solvents (Fig. 2c), one can perform a multistage synthesis. As a rule, lanterns are used once and thrown away after the last stage ("cutting off" a complex final product from the support).

Lanterns (Fig. 6) facilitate the technique of multistage syntheses of large combinatorial libraries, and the quantities of substances, isolated at the last stages $(5-50 \mathrm{mg})$, are more than sufficient for biological tests. The main problem of the lantern technique is logistic in nature, since one should learn how to record correctly the "fate" of each cylinder (not to disorder cylinders in the course of multistage syntheses). To this end, each lantern should be labeled in its specific way. Three approaches are known. The most reliable (and costly) is the so-called Irory technology, when each lantern is provided with a microchip (Fig. 6d), and a special electronic device is required to record and read off from microchips what reactions each lantern should be introduced in (or has (a)

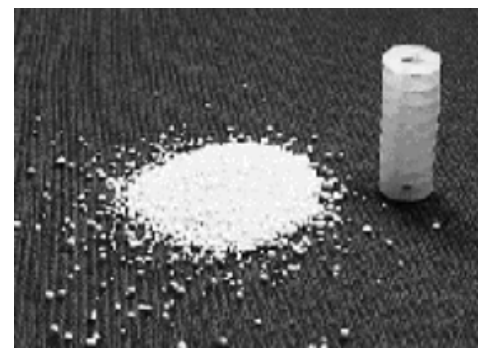

(e) (b)

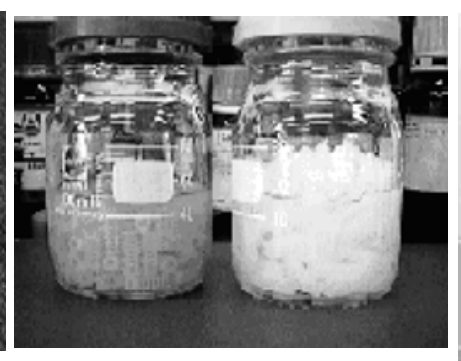

(c)

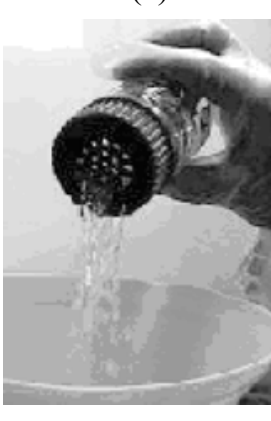

(g) (d)

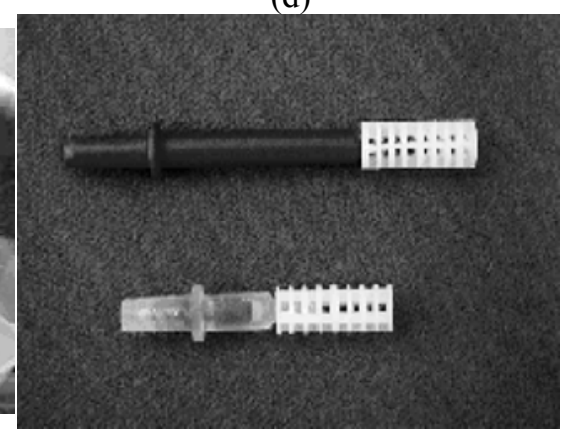

(h)
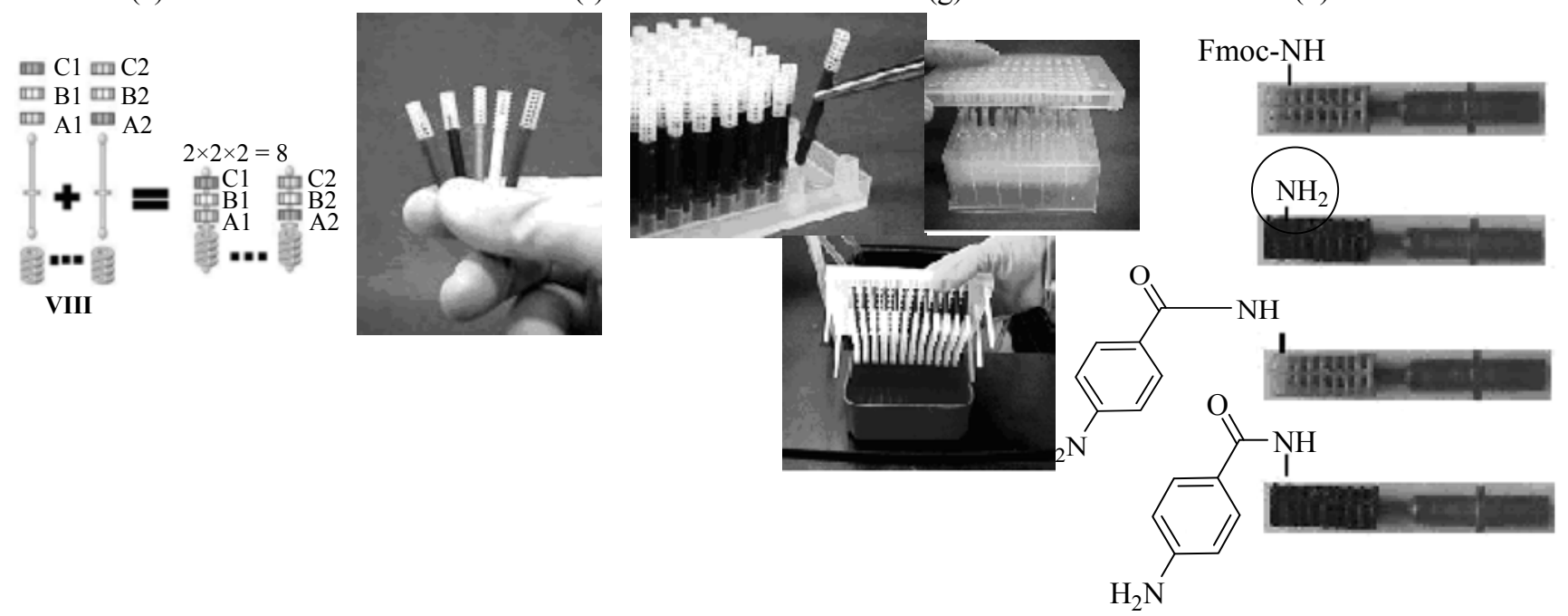

Fig. 6. Technique of the solid-phase synthesis on lanterns (see text). 
(a) Existing protocol with lanterns: ureas from amines

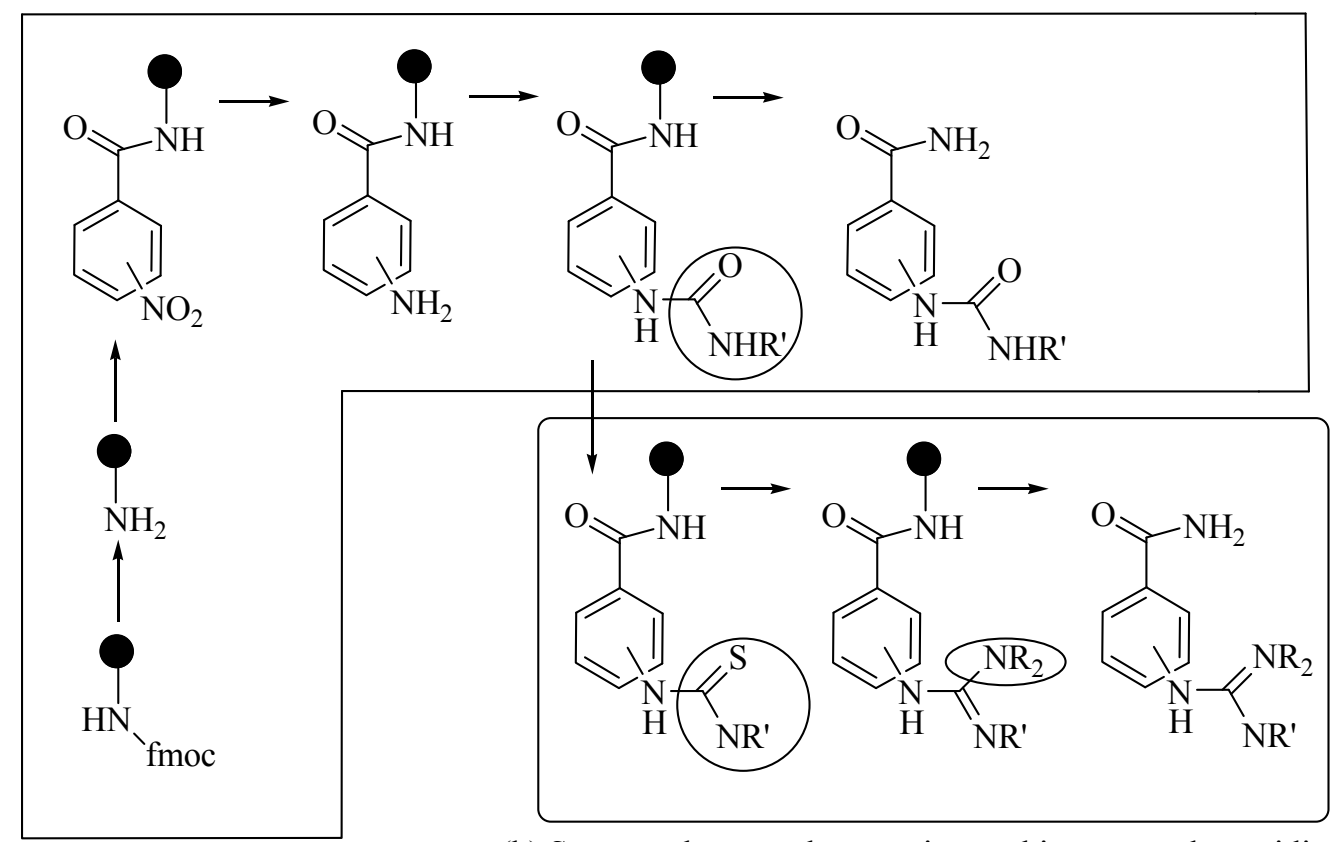

(b) Suggested protocol: extension to thioureas and guanidines

Fig. 7. (a) Procedure of diarylurea synthesis, recommended by the producer and (b) synthetic protocol for preparing thioureas and guanidines, optimized as a training task for students.

already been introduced in). A simpler approach is to fix lanterns in the cap of a billet with numbered holes (Fig. 6g) and keep a record by lantern numbers. And, finally, one can fix colored plastic pins on lanterns and mark the reagents already used for synthesis with colored labels or rings (Figs. 6d, 6e, and 6f). This approach is convenient in the case of small libraries.

Choice of model reaction. The Mimotopes's website (www.mimotopes.com) reports a great number of examples of efficient usage of lantern in the synthesis of diverse libraries. Out attention was arrested by a simple synthetic sequence leading to $N, N$-diarylureas [10] (Fig. 7a).

The key stages of this process are quite simple: a $m$-(or $p$-)nitrobenzoic acid residue is fixed on a lanern, and then the nitro group is reduced, and the aniline fragment is reacted with isocyanates. Attempting to correlate the structure of expected products with their potential biological activity, we noticed that close structural relatives of diarylureas, viz. diaryl- and triarylguanidines, are well-known medicines (Fig. 8). (Note that thiomorphine and its structural analogs in the libraries, too, contain the guanidine motif).
It was not too difficult to associate the possible synthetic route to guanidines with the aniline intermediate in Fig. 7a: A thiourea residue can be obtained in a high yield by simply replacing isocyanates with isothiocyanates (Fig. 7b). This procedure is welldeveloped in a usual liquid-phase version [11]. Thoureas, in their turn, can be easily converted into guanidines by well-developed (again, in solutions) published procedures [12]. Just this sequence (probably, never realized in the solid-phase version) formed the basis of a task at the special student laboratory at the MSU.

Required reagents and equipment. Lanterns VIIXI, 1.5-ml Eppendorf-type plastic tubes (50), and great number of serum vials are required. For removing the protective group from the resin, a $20 \%(\mathrm{v} / \mathrm{v})$ solution of piperidine in DMF is prepared. The consumption of reagents is not very high, mostly $1-5 \mathrm{~g}$. Triethylamine and isomeric meta- and para-nitrobenzoyl chlorides (the labels on the bottles are A and B) are required for the acylation stage. Reduction is performed using $\mathrm{SnCl} 2 \times 2 \mathrm{H}_{2} \mathrm{O}$. The isothiocyanates used are metachlorophenyl isothiocyanate (I) [13] and furfuryl 


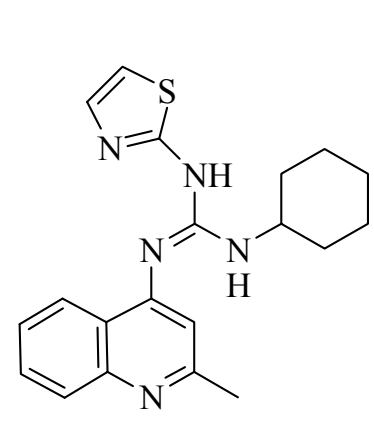

Timegadine antiinflammatories

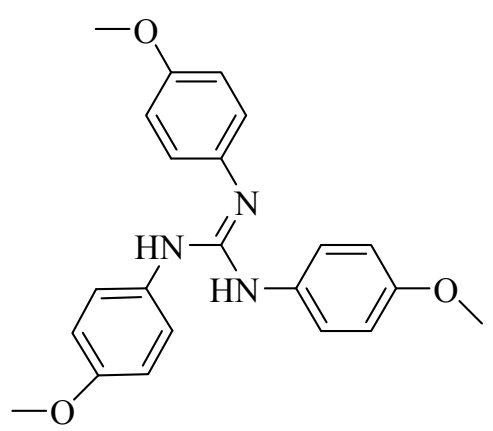

Phenodianisyl local anesthetics

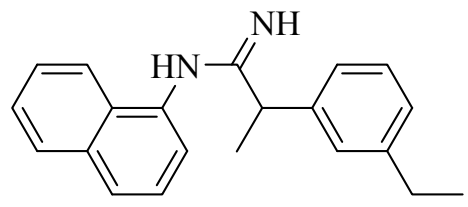

Aptiganel neuroprotectives

Fig. 8. Drugs of the di(tri)arylguanidine series in the Merck Index.

isothiocyanate (II) [14], which were prepared by known procedures. To convert thioureas into guanidines, $\mathrm{NaIO}_{4}$ and three amines are required: morpholine $(\alpha), m$-toluidine $(\beta)$, and benzylamine $(\gamma)$. For the cleavage state we take trifluoroacetic acid; lanterns are washed with methanol and DCM.

Transformation sequence and methodical notes. In the work with lanterns, one of the main disadvantages of solid-phase synthesis, viz. difficult control of the degree of progress of multistage reactions, becomes the most evident. Spectral methods are unsuitable. (Actually, plastic pins are difficult to place into spectrometer ampules or cells). At the same time, accumulation of incompletely reacted functional groups (at five or six planned stages) may dramatically affect the purity of the final product. A stage-to-stage purity control is possible: by "cutting-off" intermediates from the support after every further stage. This method is complicated by another reason: In is only with a final product (with a high molecular weight) that one deals with weighable quantities of substance, whereas the quantities of low-molecular intermediates will be negligibly small.

Reaction progress is optimally (and what is more, visually) controlled as follows. Let us note (see Fig. 7) that at the first four stages the amino group is either present on the resin surface (the first time after protection removal and the second time after $\mathrm{NO}_{2}$ reduction) or absent (on the initial lanterne, in the nitrobenzamide fragment, and in aryl thiourea). Such an alternating appearance and disappearance of the amino group can be detected by means of the Kaiser test. ${ }^{1}$ It was found (see Fig. 6h) that this test is quite

\footnotetext{
${ }^{1}$ See the paper of Babaev and Ermolant'ev in the present issue.
}

effective, i.e. it makes sense to use a control lantern at each stage (develop it with ninhydrin and then throw away). In practice, lanterns are sprayed with a ninhydrin solution and heat for a short time with a hot air (heat gut or hair drier). In the case of diaryl thioureas, control removal of an intermediate from the support and assessment of its purity by NMR were performed. The purity of final guanidines was controlled by TLC, and their composition was determined by mass spectrometry (direct inlet).

The overall sequence and logistics of transformations on 7 lanterns (plus 4 control lanterns) is shwn in Scheme 9. Let us consider the stages in more detail.

(1) Protection removal. Lanterns containing the Rink resin $\left(\mathrm{R}-\mathrm{CH}_{2}-\mathrm{NH}-\mathrm{Fmoc}\right)$ were trated with a piperidine solution to remove the protective group. The ninhydrin test on a control lantern is positive.

(2) Acylation of the free amino group of lantern $\mathbf{L X}$ (see the denotation in Scheme 9) with para- and metanitrobenzoyl chlorides A and B gives resins LXA and LXB. The ninhydrin test on a control lantern is negative.

(3) Reduction of the nitoraryl group to aniline with $\mathrm{SnCl}_{2}$. (The codes of the resulting substances is unchanged.) The ninhydrin test on a control lantern is positive.

(4) Formation of diaryl thioureas LXAI, LXAII, and LXBII by the reaction of the amino group with isothiocyanates I and II. The ninhydrin test on a control lantern is negative.

(5a) Cutting-off of diaryl thioureas XAI, XAII, and XBII with trifluoroacetic acid (TFA), determination of 
Stage 1. Removal of Fmoc protection

\section{F \\ Stage 2. Reaction with benzoyl chlorides A and $\mathrm{B}$}

Scheme 9.

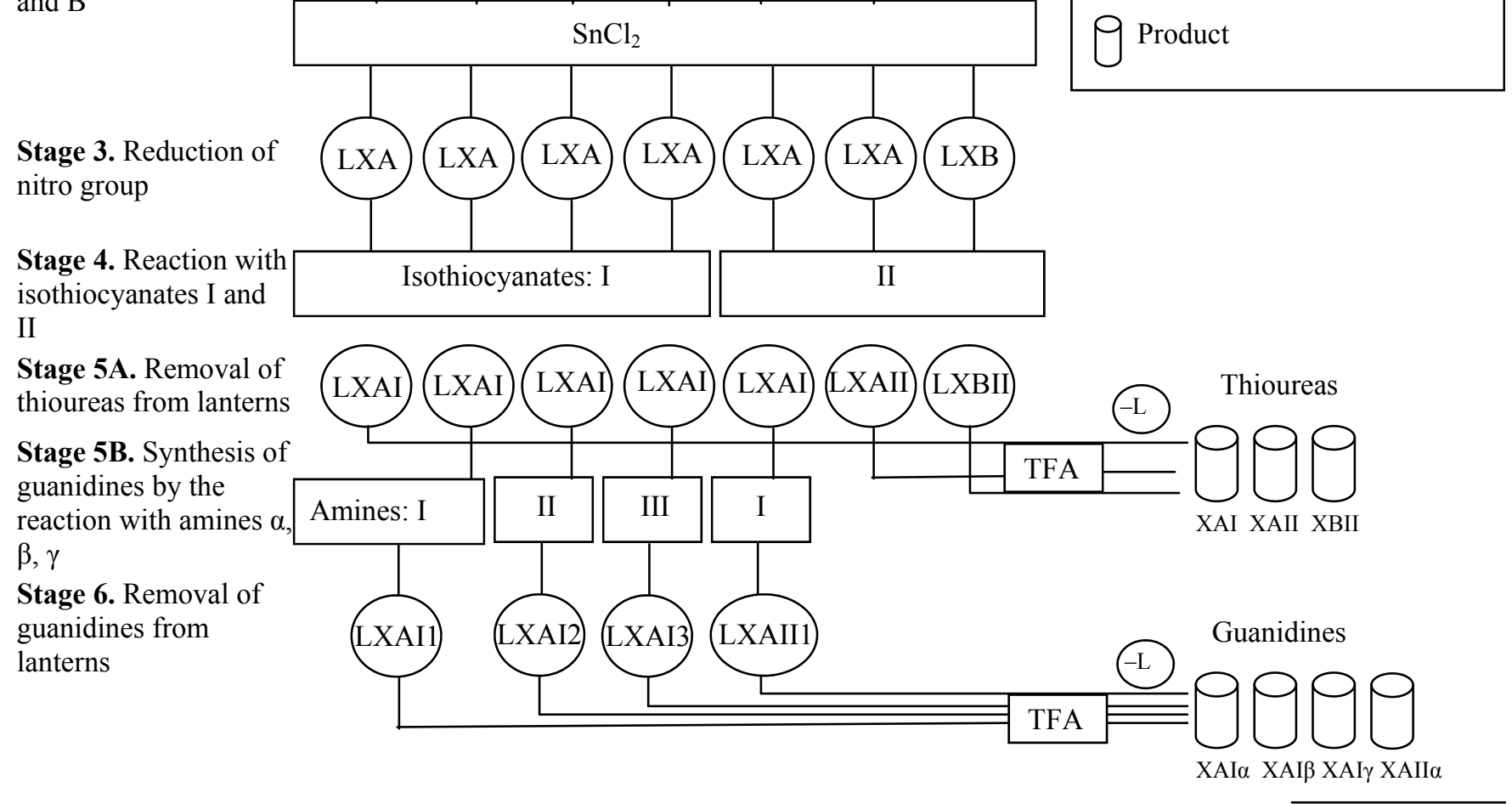

the yield (about $10 \mathrm{mg}$ ), and measurement of the NMR spectrum.

(5b) reatment of the lanterns from experiment (4) with amines $\alpha, \beta$, and $\gamma$. Preparation of guanidines LXAI1, LXAI2, LXAI3, and LXAII1.

(6) Cutting-off of guanidines XAI $\boldsymbol{\alpha}, \mathbf{X A I} \boldsymbol{\beta}, \mathbf{X A I} \boldsymbol{\gamma}$, and XAII $\alpha$ with TFA (about $10 \mathrm{mg}$ ) and mass spectral ananlysis of the isolated products.

Scheme 9 shows consecutive steps which were undertook to optimize the task. Theoretically, $2 \times 2 \times 3=$ 12 substances would be expected. The absence of certain combinations is explained by the fact that что $p$-nitrobenzoyl chloride B forms an unsatisfactorily unclear intermediate, which was found out at an early purity control stage (analysis of thioureas). Thiourea XAII (from furfuryl isothiocyanate II) gave a satisfactory ${ }^{1} \mathrm{H}$ NMR spectrum (Fig. 9a), but analysis of the guanidine obtained from this thiourea revealed a great number of admixtures (probably, formed by side reactions involving the furan ring).

In this connection we suggested to students for practical implementation only a part of Scheme 9, specifically, to use one benzoyl chloride (A), one isothiocyanate (I), and three amines, to obtain one thiourea (XAI) and three guanidines (XAI $\alpha$, XAI $\beta$, and $\mathbf{X A I} \boldsymbol{\gamma})$.

Preparation of $N, N^{\prime}, N^{\prime \prime}$-trisubstituted guanidines on lanterns. Before lesson, the teacher demonstrates a negative Kaiser test for a standard lantern. Each student obtains 8 lanterns.

Stage 1. Removal of Fmoc protection.

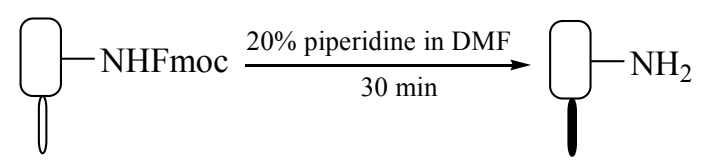

Eight lanterns are placed in $1.5-\mathrm{ml}$ plastic tubes (Eppendorf-type), and $1 \mathrm{ml}$ of $20 \%$ piperidine in DMF 

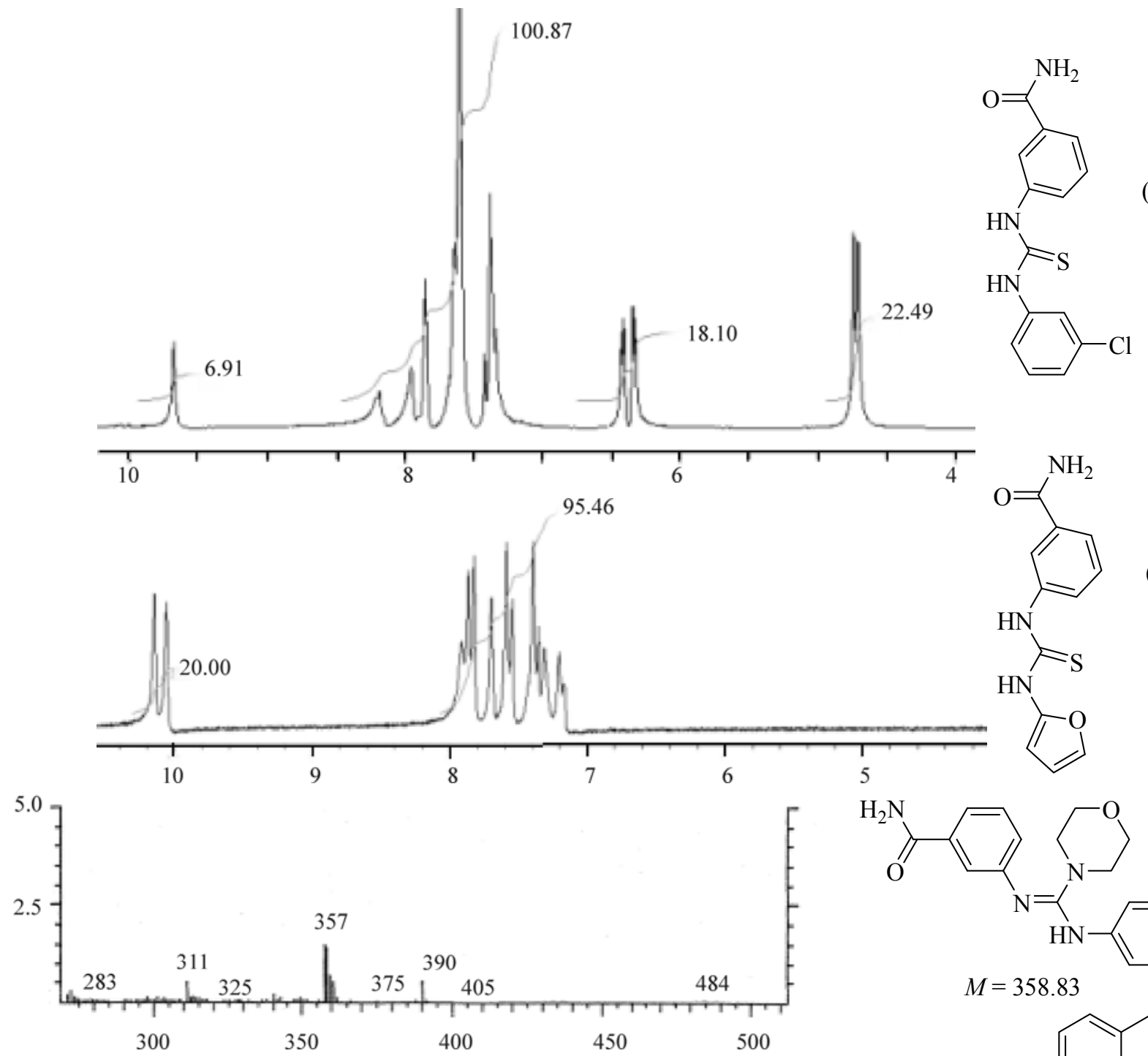<smiles>NC(=O)c1cccc(/N=C(/Nc2cccc(Cl)c2)N2CCOCC2)c1</smiles>
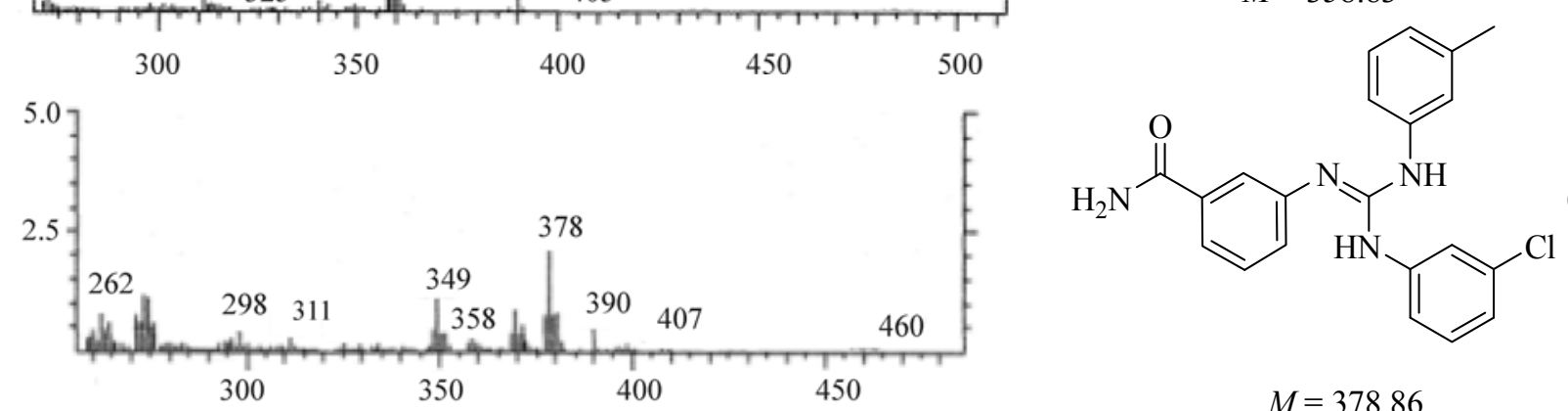

(c)
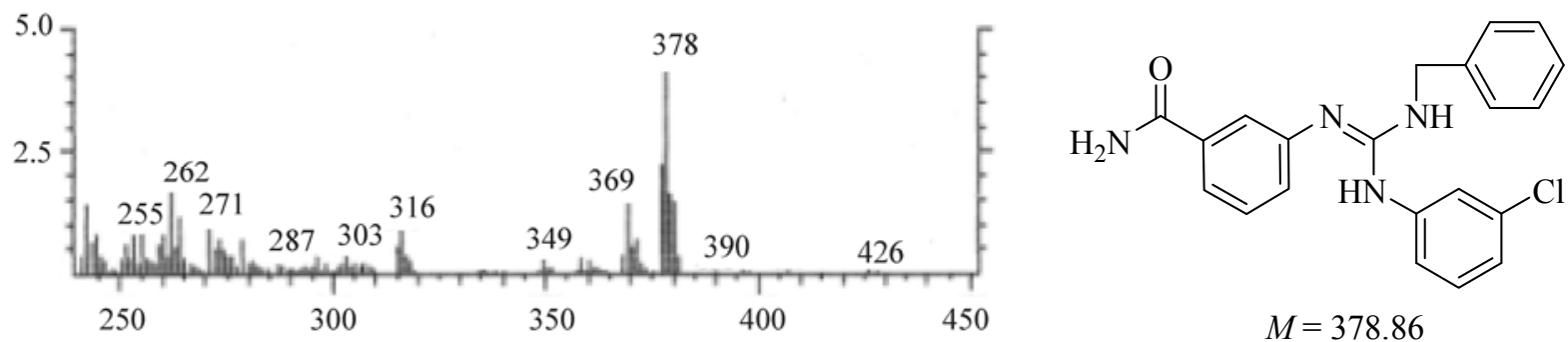

$M=378.86$

Fig. 9. ${ }^{1} \mathrm{H}$ NMR spectra of (a) thiourea XAII and (b) thioureas XAI. (c) Mass spectra of final guanidines XAI $\boldsymbol{\alpha}$, XAI $\boldsymbol{\beta}$, and XAI $\gamma$. 
is added to each tube. After $1 \mathrm{~h}$ the sticks are successively washed with DMF $(3 \times 1 \mathrm{ml})$, methanol $(3 \times 1 \mathrm{ml})$, and DCM $(3 \times 1 \mathrm{ml})$ and transferred into new tubes. The control lantern shows a positive Kaiser test.

Stage 2. Acylation of amino group.

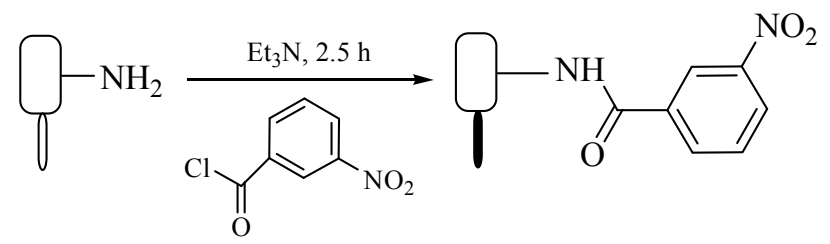

Seven lanterns are placed into plastic tubes, and $1 \mathrm{ml}$ of a $1 \mathrm{M}$ solution of meta-nitrobenzoyl chloride (0.001 mol, $0.185 \mathrm{~g}, \sim 28 \mathrm{equiv})$ and triethylamine (0.001 mol, $0.1 \mathrm{~g}, 0.14 \mathrm{ml}, \sim 28$ equiv) in DCM is added to each tube. The reaction mixture is left overnight, after which the lanterns are successively washed with DCM $(3 \times 1 \mathrm{ml})$, methanol $(3 \times 1 \mathrm{ml})$, and DMF $(3 \times 1 \mathrm{ml})$. The Kaiser test was negative.

Stage 3. Reduction of nitro group.

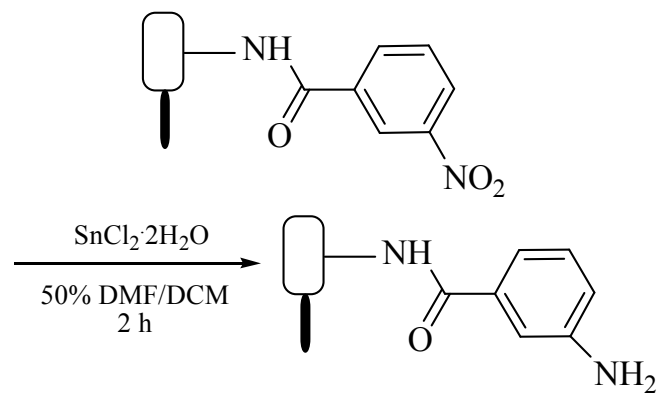

Six lanterns are placed into plastic tubes, and $1 \mathrm{ml}$ of $1 \mathrm{M} \mathrm{SnCl} 2 \times 2 \mathrm{H}_{2} \mathrm{O}$ in DMF (i.e. $0.001 \mathrm{~mol}$ of reducer). After a day, lanterns are successively washed with $\mathrm{DMF}(3 \times 1 \mathrm{ml}), \mathrm{DCM}(3 \times 1 \mathrm{ml})$, methanol $(3 \times$ $1 \mathrm{ml})$. The Kaiser test is positive.

Stage 4. Coupling with isothiocyanate.

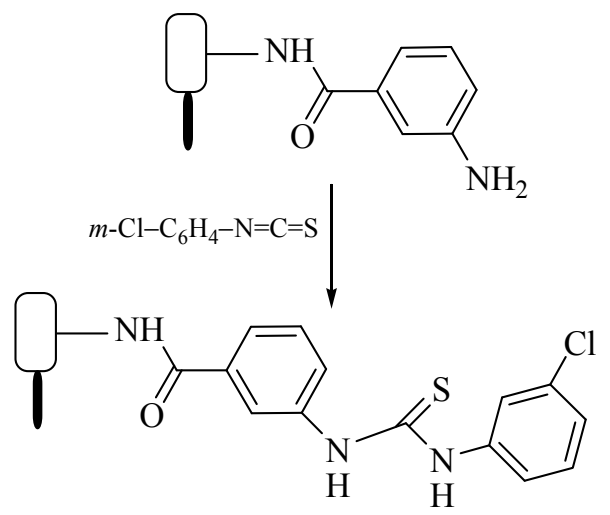

Five lanterns are placed into plastic tubes, and $1 \mathrm{ml}$ of a $1 \mathrm{M}$ solution of meta-chlorophenyl isothiocyanate $(0.001 \mathrm{~mol}, 0.169 \mathrm{~g}, 0.14 \mathrm{ml})$ in methanol is added to each tube. They are left overnight and then successively washed with methanol $(3 \times 1 \mathrm{ml})$, DCM $(3 \times 1 \mathrm{ml})$, and DMF $(3 \times 1 \mathrm{ml})$. The Kaiser test is negative.

Stage 5A. Cleavage of amide and separation of final thiourea XAI.
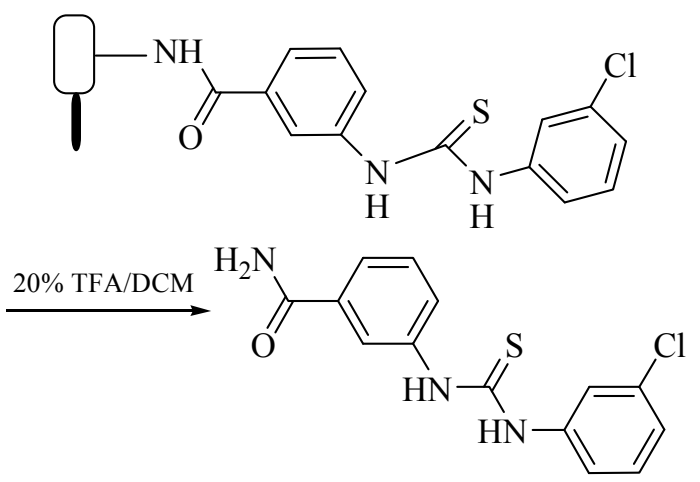

One of the lanterns is placed into a plastic tube, $1 \mathrm{ml}$ of a $20 \%(\mathrm{v} / \mathrm{v})$ solution of TFA in DCM is added, and the mixture is left to stand for $1 \mathrm{~h}$. The solution is transferred to a serum vial, and the lantern is additionally washed with DCM $(3 \times 1 \mathrm{ml})$. The combined fractions is first concentrated in air, transferred in a tube, and further concentrated in a vacuum drying oven.

$N$-( $m$-Chlorophenyl)- $N^{\prime}$-( $m$-phenylcarbamide)thiourea (XAI), $10 \mathrm{mg}, R_{\mathrm{f}}=0.7$ (Silufol, $\mathrm{CHCl}_{3} / \mathrm{MeOH}=8 / 2$ ), is obtained. According to TLC, the product contains no admixtures. The ${ }^{1} \mathrm{H}$ NMR spectrum (Fig. 9) contains no extra signals and completely fits the structure.

Stage 5B. Guanidation.
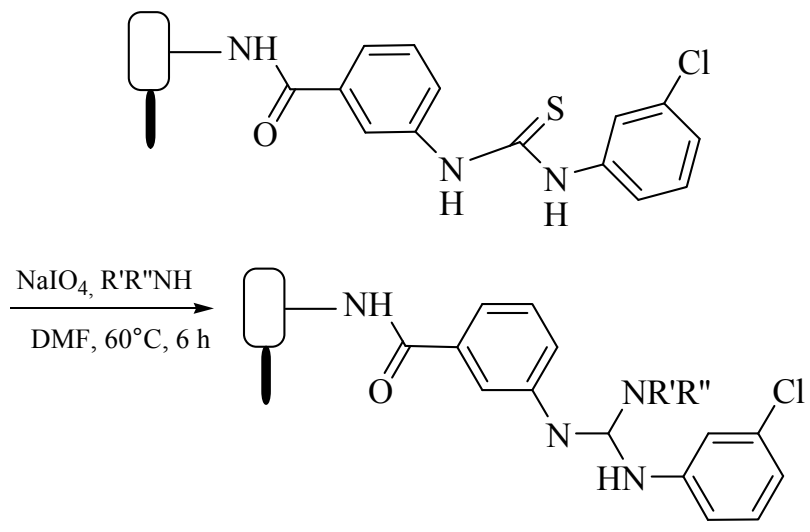
The three remaining lanterns are placed into plastic tubes labeled 1, 2, and 3, and $1 \mathrm{ml}$ of a freshly prepared solution of $\mathrm{NaIO}_{4}(0.1 \mathrm{~g}, 0.00046 \mathrm{~mol})$ and then a solution of corresponding amine I-III $(0.0007 \mathrm{~mol})$ in DMF are added to each tube. The reaction mixtures are heated for $6 \mathrm{~h}$ at $60^{\circ} \mathrm{C}$ and left overnight at room temperature. Precipitate formation is observed in all the cases. The laterns are washed with water $(5 \times 1 \mathrm{ml})$, DMF $(3 \times 1 \mathrm{ml})$, methanol $(3 \times 1 \mathrm{ml})$, and DCM $(3 \times 1 \mathrm{ml})$.

Stage 6. Cleavage of amide and separation of the final guanidine.

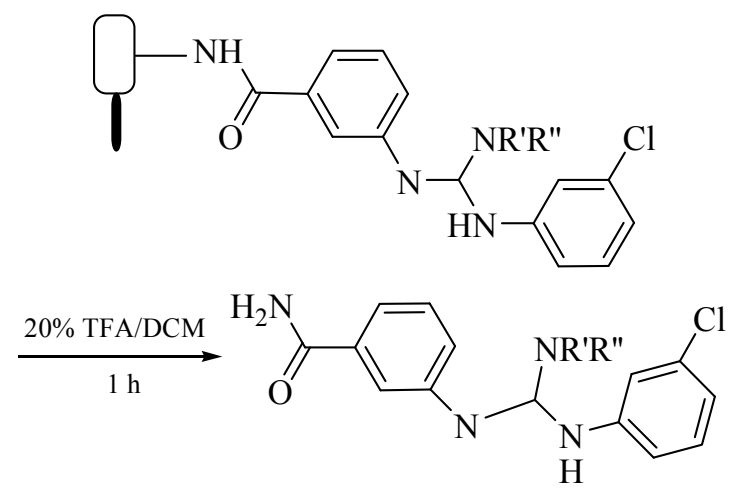

The tubes with lanterns are charged with $1 \mathrm{ml}$ of $20 \%$ TFA in DCM and left to stand for $1 \mathrm{~h}$. The solutions are transferred to serum vials with numbers, and the lanterns are additionally washed with DCM $(3 \times 1 \mathrm{ml})$. The combined fractions are concentrated first in air, transferred into new weighed tubes, and further concentrated in a vacuum drying oven to isolate $8-12 \mathrm{mg}$ of the final guanidine. All the three products have close $R_{\mathrm{f}}$ values $(\sim 0.4)$ on Silufol $\left(\mathrm{CHCl}_{3} / \mathrm{MeOH}=\right.$ $8 / 2)$. By TLC, a minor admixture $(5-10 \%)$ with $R_{\mathrm{f}}=$ 0.8 was detected. No further purification was performed. The mass spectra show molecular ion peaks with expected $m / z$ (Fig. 9b).

\section{ACKNOWLEDGMENTS}

The authors are grateful to Prof. V. Scott (USA, Indiana) for consultations and procedures, as well as to student A. Nevskaya for help in their translation. Bags with resins, spectral data for products, and initial procedure (for adaptation to a training task) was provided by $\mathrm{PhD} \mathrm{Yu}$. Sandulenko (CDRI). The set of lanterns was provided by Mimotopes, and trial experiments with them were performed by $\mathrm{PhD}$ student A. Leont'ev.

\section{REFERENCES}

1. Babaev, E.V. and Ermolat'ev, D.S., Ross. Khim. Zh. (Zh. Ross. Khim. O-va im. D.I. Mendeleeva), 2009, vol. 53 , no. 5 , p. 42

2. O'Donnell, M.J., Zhou, C., and Scott, W.L., J. Am. Chem. Soc., 1996, vol. 118, p. 6070.

3. Scott, W.L., Zhou, C., Fang, Z., and O'Donnell, M.J., Tetrahedron Lett., 1997, vol. 38, p. 3695.

4. O'Donnell, M.J., Delgado, F., Dominguez, E., et al., Tetrahedron: Asymmetry, 2001, vol. 12, p. 821.

5. Scott, W.L., O’Donnell, M.J., and Alsina, J., J. Org. Chem., 2002, vol. 67, p. 2960.

6. Scott, W.L., Alsina, J., and O'Donnell, M.J., J. Comb. Chem., 2003, vol. 5, p. 684.

7. Alsina, J., Scott, W.L., and O'Donnell, M.J., Tetrahedron Lett., 2005, vol. 46, p. 3131.

8. Scott, W.L. and O'Donnel, M.J., J. Comb. Chem., 2009, vol. 11, p. 3.

9. Scott, W.L., Alsina, J., Audu, C.O., et al., Ibid., 2009, vol. 11 , no. 1 , p. 14.

10. http://www.mimotopes.com/files/pdf/ChemNote2.pdf.

11. Mozolis, V.V. and Iokubaitite, S.P., Usp. Khim., 1973, vol. 42, no. 7, p. 1310.

12. Ramadas, K., Janarthanan, N., and Pritha, R., Synlett, 1997, no. 9, p. 1053.

13. Radl, S., Coll. Czech. Chem. Commun., 1992, vol. 57, no. 3, p. 656.

14. Spurlock, L.A. and Fayter, R.G., J. Org. Chem., 1969, vol. 34 , no. 12 , p. 4035. 